SISTEMA
ELETRONICO
DE REVISTAS
SER I UfPR
DESENVOLVIMENTO
E MEIO AMBIENTE ser.ufpr.br

\title{
Abordagem interdisciplinar da problemática ambiental urbano-metropolitana: esboço metodológico da experiência do Doutorado em MA\&D* da UFPR sobre a RMC - Região Metropolitana de Curitiba**
}

\author{
Francisco MENDONÇA ${ }^{1}$
}

1 Doutor em Geografia e Professor Titular do Departamento de Geografia (DGEO) e do Programa de Doutorado em Meio Ambiente e Desenvolvimento (MA\&D) da Universidade Federal do Paraná (UFPR). Foi vice-coordenador do MA\&D, na gestão 1997-1998, e coordenador das atividades da Turma II do referido doutorado.

A produção do conhecimento humano, na sua forma científica, é uma das principais características da modernidade ${ }^{1}$. A ciência moderna é, em todas as suas características, um reflexo direto da forma de pensar e produzir conhecimento dentro dos padrões da racionalidade e filosofia moderna.

O conhecimento científico que se organizou nessa temporalidade é fortemente marcado por uma quase frenética busca de especializações, ou aprofundamento da verticalidade dos ramos específicos das diferentes ciências, por si já bastante distintas umas das outras. Como as causas para o desenvolvimento de um tal processo pareçam já bastante conhecidas, e boa parte dos epistemólogos concordam que elas estejam nos objetivos do modo de produção capitalista e, portanto, no projeto positivista, os efeitos estão a demandar dos estudiosos, permanentemente, novas abordagens e iniciativas para combater o reducionismo científico e o caos decorrentes desse processo.

Os diversos campos disciplinares do conhecimento, por muito que tenham auxiliado no desenvolvimento científico-técnico-tecnológico da sociedade, parecem ter também contribuído para a

\footnotetext{
* MA\&D - sigla que significa Programa de Doutorado Interdisciplinar em Meio Ambiente e Desenvolvimento da UFPR - Universidade Federal do Paraná.

** Este texto foi originalmente publicado no periódico Desenvolvimento e Meio Ambiente, n. 3, 2001, do próprio M\&D, tendo sido o tema central da publicação com o tema "Cidade e ambiente urbano". Republicado em: MENDONÇA, F. (Org.). Cidade, ambiente \& desenvolvimento: abordagem interdisciplinar de problemáticas socioambientais urbanas de Curitiba e RMC. Capítulo 1. Curitiba: Editora da UFPR, 2004. p. 11-29.

${ }^{1}$ Modernidade é aqui concebida como o período em que a sociedade adquire a forma de organização atual e que teria se consolidado a partir do final do século XVIII e início do XIX, conforme Berman (Berman, M. Tudo que é sólido desmancha no ar: a aventura da modernidade. São Paulo: Companhia das Letras, 1986).
} 
formação de um estado geral de crise no momento contemporâneo, crise inclusive de civilização ${ }^{2}$, que demanda de políticos, cientistas, intelectuais, etc., enfim, dos mais diversos atores sociais, ações para a superação dessa crise. É neste sentido que superar o estágio modernista da estrita e estreita divisão disciplinar do conhecimento se apresenta como um desafio aos acadêmicos e pesquisadores. É também neste sentido que o Programa de Doutorado Interdisciplinar em Meio Ambiente e Desenvolvimento se coloca.

Estudar a cidade, o fato urbano, a metropolização, não é atributo de nenhuma ciência em particular, isto porque a cidade se constitui numa verdadeira encruzilhada, na qual se encontram diferentes realidades, dinâmicas, interesses e saberes. Ela constitui, por si só, um paradoxo à realidade positivista moderna, seja porque explicita diferenças ao concentrar homens e atividades num só lugar, seja porque evidencia contradições básicas do modo de produção moderno - ao impor, por exemplo, a coexistência da miséria e da riqueza numa mesma dimensão espaço-temporal. Mas,

- O que é e como se configura o ambiente urbano-metropolitano-industrial neste contexto de paradoxos e contradições?
- Seria possível estudá-lo, numa perspectiva totalizante e holística, por meio de campos disciplinares tão individualizados e verticalizados?

Foi ao assumir o desafio do estudo de problemas ambientais numa perspectiva interdisciplinar que o MA\&D foi criado, e foi também na perspectiva de desenvolver uma nova abordagem dos problemas ambientais urbano-metropolitanos que a segunda turma do programa foi constituída. Os resultados da construção de um trabalho interdisciplinar sobre a cidade, particularmente da cidade de Curitiba e de sua região metropolitana, compõem o cerne deste texto. Embora tenha sido coordenada pelo autor deste, vários professores e pesquisadores ${ }^{3}$ participaram das atividades da turma $\mathrm{II}^{4}$, tendo, portanto, auxiliado consideravelmente na construção da presente metodologia interdisciplinar.

\section{O desafio de apreender os problemas da cidade de maneira integrada: o estudo do ambiente urbano}

A cidade é uma construção humana bastante antiga, cuja concepção genérica pode ser expressa pela aglomeração de pessoas (mais equipamentos e edificações) e seu dinamismo (atividades) num

\footnotetext{
${ }^{2}$ Vale lembrar aqui a importante reflexão de Eric Hobsbawn (Hobsbawn, E. Era dos extremos: o breve século XX (1914-1991). São Paulo: Companhia das Letras, 1998) relativa à grave crise de civilização vivida pela humanidade no final do século XX.

${ }^{3}$ De maneira direta participaram das atividades os seguintes professores: Dr. Guillermo Folladori (Antropologia/Economia), Dr. Dimas Floriani (Sociologia), Dr. Ademar Heemann (Ciência Natural/Filosofia), Dra. Maria do Rosário Knechtel (Sociologia/Pedagogia), Dr. Naldy Emerson Canali (Geografia) e Dra. Angela Damasceno Ferreira (Sociologia). Além destes, também participaram, em momentos específicos, os professores Dra. Magda Zanoni (Biologia/Sociologia - Université Paris 7), Dr. Claude Raynaut (Antropologia - Université Bordeaux II), Dr. Victor Pelaez (Economia/UFPR), Dr. Márcio de Oliveira (Sociologia/UFPR), Dr. Yannis Tsiomis (Arquitetura - Université Paris La Villete) e a Dra. Denise Pinheiro Machado (Arquitetura - PROURB/Rio de Janeiro).

${ }^{4}$ A turma II do Programa de Doutorado MA\&D foi composta por 14 (catorze) profissionais oriundos de diversas disciplinas, assim distribuídos: Alberto Pucci Junior (Informática), Cristina de Araújo Lima (Arquitetura), Emílio Trevisan (Engenharia Florestal), Gastão Octavio F. da Luz (Pedagogia), Karen F. Karam (Sociologia), Miguel Arturo C. Oliveira (Economia), Moacir Darolt (Agronomia), Paulo Roberto Delgado (Sociologia), Nelson A. Garcia dos Santos (Sociologia), Patricia T. Padilha da Silva (Farmácia), Rinaldo Claudino de Barros (Sociologia), Rodolfo Humberto Ramina (Engenharia Civil), Sônia Maria Davanso (Medicina) e Tania Lúcia G. de Miranda (Engenharia Hidráulica).
} 
determinado local ${ }^{5}$. A estruturação, a morfologia e a funcionalidade das cidades, como se observam hoje, têm, todavia, sua origem num momento bem preciso da história do Ocidente que pode ser identificado como aquele da superação das relações feudais pelas mercantis e capitalistas de produção no mundo ocidental. A cidade contemporânea constitui o melhor exemplo do projeto moderno.

O estabelecimento das relações sociais, políticas e econômicas da Era Moderna impõe uma nova dinâmica às cidades. Pontos nevrálgicos das relações capitalistas de produção, elas passam a centralizar cada vez mais a produção, o consumo, a circulação, enfim, o poder. Num tal contexto, o ambiente natural, paisagem intocada antes da intervenção humana, testemunhará transformações mais predatórias quanto mais interesses às relações de produção despertar o local, resultando no fato de algumas cidades apresentarem ambientes mais degradados que outras.

Observa-se, na modernidade, tanto uma depredação da natureza quanto o despertar da consciência para a intervenção racional ou planejada na alteração/construção do ambiente urbano. Uma vez constatada a condição inexorável da urbanização da humanidade, consubstancia-se também a necessidade do aprofundamento da reflexão sobre a vida na cidade e, portanto, de planejar ou ordenar a forma da ocupação ou do desenvolvimento dos espaços urbanos. Para tanto, e observando-se a emergência da questão ambiental contemporânea, particularmente no que concerne às condições e qualidade de vida na cidade, todos os elementos componentes do meio biótico, abiótico e social devem ser levados em consideração.
Entretanto, cerca de dois séculos de urbanização atrelada à industrialização revelam que, se em algumas localidades vários elementos de ordem tanto natural quanto social têm sido observados no processo de planejamento urbano, a ênfase ao enfoque volta-se quase que exclusivamente aos interesses econômicos. Esta conduta moderna gera ambientes urbanos altamente nocivos à maioria dos habitantes das cidades no que concerne às suas funções vitais e psicossociais, principalmente naqueles países caracterizados por um contexto socioeconômico de desenvolvimento complexo, nos quais se observa êxito econômico associado a alarmantes injustiças sociais.

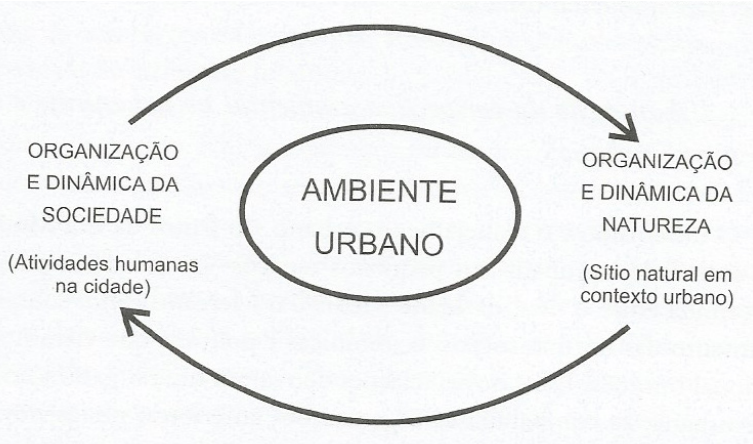

FIGURA 1 - Esquema genérico do estudo do ambiente urbano.

A racionalidade moderna, pela qual o pensamento científico foi estruturado, reservou ao conhecimento da natureza e da sociedade caminhos bastante distintos e muitas vezes opostos. Todavia, foi, sem sombra de dúvidas e ainda em um contexto positivista, a partir do emprego da Teoria de Sistemas, da compreensão da dinâmica da natureza e das preocupações de alguns cientistas e intelectuais com a interação estabelecida entre o sítio natural,

\footnotetext{
5 Para uma boa apreensão da história da cidade e de sua evolução ao longo da história humana é sempre útil recorrer a Munford, L. A cidade na história. Belo Horizonte: Itatiaia, 1965.
} 
a materialidade urbana e as atividades humanas, que a cidade passou a ser enfocada de um ponto de vista mais holístico e numa dimensão evolutiva, originando os estudos do ambiente urbano (Figura 1), como se pode observar na atualidade. A cidade moderna, por sua própria condição de campo de interações de dinâmicas naturais e sociais e sua miríade de problemas, demanda abordagens que superem as clássicas iniciativas dos campos disciplinares estanques.

A intensificação das preocupações com o ambiente urbano deriva, dentre outros, do incremento das cidades no que diz respeito ao seu crescimento e complexidade, fato aliado à agudização da queda da qualidade de vida urbana, notadamente nas cidades grandes e áreas metropolitanas.

Considerada por muitos como sendo a solução racional para o equacionamento dos problemas ambientais urbanos, a atividade de planejamento, entretanto, tem sido bastante questionada nas últimas décadas, dado que as condições de vida na cidade não apresentaram melhora significativa. Num tal contexto, inúmeras questões podem ser levantadas no sentido de melhor compreender a realidade ambiental urbana contemporânea, tais como:

- Seriam os problemas ambientais urbanos resultantes somente da ineficácia do planejamento urbano ou será que as caóticas e/ou gigantescas cidades modernas, que atraem cada vez mais imigrantes, tornaram-se impraticáveis para qualquer política de planejamento?

- Como conceber as "cidades sustentáveis", e o que seria uma "cidade sustentável"?

Questões como essas, longe de serem aqui esgotadas, apontam para o necessário aprofundamento das reflexões acerca da abordagem interdisciplinar do estudo da cidade na perspectiva ambiental, bem como para a proposição de ações visando à melhoria da gestão ambiental urbana.

\subsection{A inserção da perspectiva ambiental no urbanismo e no planejamento urbano ${ }^{6}$}

O urbanismo e o planejamento urbano são frutos da Era Moderna. A vida humana em sociedade, agrupada em pequenos espaços - a cidade -, passou por uma revolução profunda entre o final da Idade Média e o Mercantilismo, sobretudo a partir do estabelecimento das normas sociais, econômicas e políticas que vieram a caracterizar o estado nacional burguês. Estas novas relações derivaram uma organização diferenciada da sociedade urbana, se comparada às organizações anteriores; nestas novas condições sociais a cidade atesta, como bem o apontou Henri Lefebvre ${ }^{7}$, a substituição da sua condição de obra coletiva à condição de produto.

A industrialização, a produção, a circulação e o consumo de mercadorias, dentre outros, e a concentração populacional nas cidades que se intensificou nos dois últimos séculos, tanto promoveram a explosão urbana quanto introduziram paulatinamente a degradação dos ambientes urbanos. Esta realidade moderna passou então a exigir, notadamente do Estado, iniciativas no sentido de ordenar o desenvolvimento dos aglomerados humanos e a intervenção no equacionamento dos problemas daí derivados. É, certamente, num tal contexto que se observa o nascimento do planejamento urbano.

A insalubridade observada na maior parte das cidades industriais europeias no século XIX

${ }_{6}$ Parte deste item compõe o artigo de Mendonça, F. A. intitulado Geografia, planejamento urbano e ambiente. In: Souza, A. J. et al. (Org.). Paisagem, território, região: em busca da identidade. Cascavel: Unioeste/AGB, 2000. p. 39-48.

7 Lefebvre, H. O direito à cidade. São Paulo: Moraes, 1991. 
demandou ações corretivas voltadas ao resgate da qualidade do ambiente citadino, mesmo se as primeiras intervenções tenham ocorrido de maneira notadamente pontual no corpo de algumas áreas urbanas. $\mathrm{O}$ apelo à qualificação estética de poucas e esparsas porções da cidade, todavia, também ganhou importância tanto quanto a busca da higienização, fato revelador das contradições da sociedade capitalista na organização do espaço urbano.

É interessante notar que o surgimento do urbanismo moderno no século XIX tenha refletido em duas correntes principais de então - a naturalista e a humanista - uma tão expressiva preocupação com a interação entre a sociedade e a natureza, com aquilo que na atualidade pode ser genericamente concebido como uma perspectiva ambientalista do planejamento urbano. Esta visão da cidade muda com a passagem do século e o que se observa é o predomínio das ideias da modernidade que se concretizam no urbanismo progressista; este, ao contrário das duas correntes anteriores, baseia-se no avanço da técnica com forte ênfase na indústria e na circulação (meios de transporte como o automóvel e o avião), revelando uma completa consonância com os ideais da modernidade capitalista. A vida na cidade registra a troca da rua (do público, do coletivo) pela casa (o particular, o individual), ou seja, a substituição do cidadão pelo citadino, associada à funcionalidade produtiva, expressa no esquartejamento do tecido urbano (ou zoneamento) em áreas com funções bastante definidas (zona residencial, zona comercial, zona industrial, zona de lazer, zona de serviços, etc.).

Esta nova cidade exige, então, sistemas de controle muito bem organizados para coordenar e disciplinar o desenvolvimento urbano, fato que logra grande sucesso nos países cuja industrialização e economia já se encontravam consolidadas no início do século XX. Os países não desenvolvidos, pela exacerbada debilidade do controle social e ambiental, ante as imposições da economia, atestam um completo empobrecimento das condições de vida e do ambiente urbano.

Uma perspectiva particular de planejamento foi desenvolvida na França a partir de meados do século XX, o aménagement du territoire, que buscava ir além da funcionalidade urbana que tão marcadamente caracteriza o urbanismo modernista; para Tarlet $t^{8}$, o termo teria sido forjado "para designar as intervenções coletivas e voluntárias sobre o plano espacial ou geográfico". Na sua visão, mesmo se considerando a representativa política de ordenamento e gestão do território levada a cabo nesta perspectiva, o termo reveste-se de considerável ambiguidade, ou seja, não constitui uma noção muito clara de estudo e intervenção espacial. Para diferenciá-lo do planejamento, propõe que o termo seja reservado para "designar uma abordagem global, em nível da concepção, dos diferentes aspectos e das transformações voluntárias em curso ou em projeto num determinado espaço".

No caso brasileiro, tanto a política do aménagement du territoire quanto o planejamento global da cidade não obtiveram ressonância significativa. Ao se observar de maneira mais detalhada o desenvolvimento das cidades brasileiras, a intervenção via planejamento urbano deu-se sobretudo de forma pontual, tanto ao se considerar o tecido urbano quanto no enfoque dos elementos que o compõem. Houve e há, de forma explícita, uma maior ênfase ao desenvolvimento econômico das cidades em detrimento das condições e qualidade de vida da

${ }^{8}$ Tarlet, J. La planification ecologique. Paris: Economica, 1985. 
população, mesmo na cidade brasileira que se quer exemplo de eficácia do planejamento urbano e "capital ecológica" - a cidade de Curitiba, capital do Estado do Paraná.

Lopes ${ }^{9}$, ao elaborar em obra recente uma análise relativa aos aproximadamente dois séculos de teorias de planejamento e tendo como base a obra de John Friedman, concluiu serem quatro as escolas de pensamento ligadas ao planejamento urbano e inúmeras as teorias que se destacam na sua história evolutiva. Na sua leitura, as quatro escolas são: a) a Análise Política, b) o Aprendizado Social (ambas nascidas a partir de 1930), c) a Reforma Social, d) a Mobilização Social, estas com uma origem que remonta ao início do século XIX. Essas escolas são, como o observado, centralizadas na abordagem social, política e econômica do planejamento, sendo a abordagem ambiental fracamente enfocada, e, quando aparece, está envolvida no âmbito das teorias e na elaboração de propostas. De toda maneira, a cidade intencional também não explicita de forma muito clara a vertente ambiental, sendo somente na elaboração do diagnóstico que observa uma breve alusão a esta preocupação.

Araújo $^{10}$, ao analisar o desenvolvimento do planejamento regional no Brasil, deixou claro o fato de que, no âmbito do planejamento, a preocupação governamental sempre esteve ligada, prioritariamente, à organização econômica do território e à consequente inserção do país no mercado industrial mundial. Neste contexto, a natureza ou o ambiente natural foram sempre tomados como recursos naturais disponíveis à apropriação e à reprodução econômica. Na sua concepção, mesmo assim o planejamento veio perdendo, paulatinamente, impor- tância no campo da ação governamental, sendo que a partir de final da década de 80 as tentativas foram sobretudo de gerir a crise, ou seja, remediando-se o presente e negligenciando-se o futuro.

A mudança que se observa na evolução da atividade de planejamento que, de caráter eminentemente economicista, abre-se para a abordagem ambiental, é sobretudo resultante de pressões oriundas da crise ambiental que se acirrou nas três últimas décadas, pois “"...] no momento em que se elaboram sistematicamente planos diretores ao crescimento urbano e há preocupações especiais com nossas áreas metropolitanas, torna-se absolutamente necessário que os estudos não se atenham apenas aos aspectos econômicos" (Monteiro, 1976, p. 133). Uma tal mudança de concepção e prática é, indubitável e paradoxalmente, um dos bons resultados da crise.

No que concerne ao caso brasileiro, os reflexos do movimento ambientalista contemporâneo no planejamento urbano se fazem sentir de maneira direta até mesmo na Constituição Federal promulgada em 1988, que estabeleceu a necessidade da elaboração de planos diretores do desenvolvimento urbano para os municípios com população acima de 20.000 habitantes.

Este artifício, mesmo deixando em aberto a determinação temporal para a elaboração dos referidos planos, configura um considerável avanço legal para a orientação e normatização do desenvolvimento das cidades; considerando o momento histórico marcado por amplos debates relativos à qualidade e condições de vida urbana, a abordagem ambiental passou a ser uma preocupação recorrente nos planos diretores.

\footnotetext{
9 Lopes, R. A cidade intencional: o planejamento estratégico de cidades. Rio de Janeiro: Mauad, 1998.

${ }^{10}$ Araújo, T. B. A experiência do planejamento regional no Brasil. In: Lavinas, L. et al. (Org.). Reestruturação do espaço urbano e regional no Brasil. São Paulo: Anpur, Hucitec, 1991. p. 87-96.
} 
Mesmo observando-se a evolução e importância adquiridas pelo planejamento urbano no Brasil nas últimas décadas, podem-se constatar correntes de pensamento que, sobretudo nos últimos dez anos, têm colocado esta atividade em questionamento, o que pode ser verificado na concepção de Harvey ${ }^{11}$ sobre a cidade no final do século XX. Uma perspectiva dessas novas correntes procura tratar da cidade por meio da gestão urbana, entendendo que assim a abordagem tomaria a cidade de um ponto de vista mais global, e não de um planejamento urbano que a teria tratado de forma estanque, essencialmente funcionalista e idealista. Nesta visão, o momento presente evidenciaria a queda do planejamento urbano, pois a sua aplicação na segunda metade daquele século, fortemente atrelada à economia, estaria, dentre outras causas, na gênese do caos urbano predominante no país.

Esta situação não é, todavia, uma constatação inovadora, pois Monteiro ${ }^{12}$ há mais de três décadas já a evidenciara ao afirmar que

[...] o planejamento não pôde, ainda, firmar-se como fato inquestionável e aceito integralmente. Não lhe falta, de um lado, certa dose de descrédito, a ponto de se lhe considerar os diagnósticos como tão opressivos ao doente quanto sua própria doença, ou mesmo uma doença paralela. De outro lado, pode ser visto como uma prática fundamental e indispensável ao curso da ação do poder público.

É a partir dessas mudanças, decorrentes da eclosão da questão ambiental e sua inserção na pauta das principais discussões internacionais nas últimas décadas, que se observa um redirecionamento das práticas sociais. É nesse novo contexto que a atividade de planejamento evidencia a necessidade do envolvimento mais aprofundado da dimensão ambiental na condução da gestão urbana.

\section{0 estudo da problemática ambiental da RMC: a experiência do MA\&D - esboço metodológico}

Os anos de 1994-95 marcaram um período de intensas reflexões do Comitê Científico do Curso de Doutorado em Meio Ambiente e Desenvolvimento na busca da definição da área de estudo da turma II, cujo início de atividades se deu em fevereiro de 1996. Ao levantar inúmeros problemas concernentes à relação sociedade-natureza nos estados do Paraná, São Paulo e Santa Catarina, notadamente na porção oriental destes e que apresenta considerável proximidade com a sede do curso, um se destacou dos demais: o considerável paradoxo existente entre a imagem veiculada nacional e internacionalmente e as reais condições socioambientais vivenciadas na cidade de Curitiba e na RMC, sobretudo quando observado ante a realidade da urbanização brasileira ${ }^{13}$.

Levantando, de maneira introdutória, alguns elementos-chave para a análise do paradoxo identificado, pôde-se constatar que nos últimos 30 anos foram sendo criadas, paulatinamente, década a década (Tabela 1), imagens que ressaltam a positividade da cidade e sua expressividade em âmbito local-regional, nacional e mesmo internacional.

\footnotetext{
${ }^{11}$ Harvey, D. A condição pós-moderna. São Paulo: Hucitec, 1992.

${ }^{12}$ Monteiro, C. A. F. Teoria e clima urbano. São Paulo: Igeo/USP, 1976.

${ }^{13}$ Das muitas obras do geógrafo Milton Santos relativas ao estudo da urbanização, vale destacar, neste particular relativo à urbanização brasileira, três: O espaço dividido (Rio de Janeiro: Francisco Alves, 1979), A urbanização brasileira (São Paulo: Hucitec, 1993) e A natureza do espaço: técnica e tempo, razão e emoção (São Paulo: Hucitec, 1996).
} 
TABELA 1 - Curitiba e suas imagens de positividade

\begin{tabular}{c|l|l}
\hline \multicolumn{1}{c|}{ Década } & Imagem & Positividade \\
\hline 1970 & Exemplo de Planejamento Urbano & $\begin{array}{l}\text { Cidade polinucleada - desconcentração urbana } \\
\text { Solução sistema transporte urbano }\end{array}$ \\
\hline $1980 / 1990$ & Capital do Primeiro Mundo & $\begin{array}{l}\text { Eficácia do planejamento urbano } \\
\text { Solução sistema transporte urbano } \\
\text { Qualidade de vida urbana }\end{array}$ \\
\hline 1990 & Capital Ecológica & $\begin{array}{l}\text { Área verde/habitante } \\
\text { Qualidade de vida urbana } \\
\text { Eficiência do sistema transporte urbano }\end{array}$ \\
\hline 2000 & Capital Social & Condições e qualidade de vida urbana \\
\hline
\end{tabular}

Neste contexto, muitos questionamentos foram então lançados, tais como:

- Será mesmo que Curitiba e sua região metropolitana comprovam a existência de boas práticas de planejamento urbano? De que tipo de planejamento urbano? Participativo e democrático, ou centralizado e tecnocrático?

- Qual teria sido a parcela da população da cidade beneficiada pelas bem-sucedidas experiências de planejamento urbano?

- Qual o conceito de "Capital ecológica"? Teria Curitiba características de uma cidade ecologicamente correta?

- Quais seriam as características da cidade que a ressaltariam como sendo uma Capital de Primeiro Mundo? Poderia mesmo existir uma Cidade de Primeiro Mundo no Terceiro Mundo?

- Qual o papel de Curitiba como polo de uma região metropolitana? Qual a repercussão de suas realizações perante os municípios por ela metropolizados?

- Qual a importância da dimensão ambiental nos processos de produção do espaço urbano-metropolitano em Curitiba e Região Metropolitana?
- Por que, a despeito de tão positiva imagem, vivenciam-se tantos problemas socioambientais em Curitiba e RMC?

Todos esses questionamentos culminaram com a construção da temática aglutinadora dos estudos da turma II, cujo objetivo principal foi a análise das condições e qualidade de vida em Curitiba e sua região metropolitana.

\subsection{A formação disciplinar como base para a interdisciplinaridade: teoria, empiria e problemática comum}

Não há proposição metodológica única para a produção do conhecimento numa perspectiva interdisciplinar, aspecto que ressalta tanto a característica científica contemporânea de suplantar as perspectivas positivistas e isolacionistas dos diversos campos disciplinares quanto o momento de crise paradigmática da ciência frente à questão ambiental ${ }^{14}$. Contudo, para a construção de abordagens interdisciplinares, há que se partir de uma consolidada base disciplinar, e a abordagem do meio ambiente se reveste de uma excelente oportunidade

\footnotetext{
${ }^{14}$ Interessantes proposições teórico-metodológicas acerca da abordagem ambiental numa perspectiva interdisciplinar podem ser consultadas em Cadernos de Desenvolvimento e Meio Ambiente (n. 1, 2, 3, 4 e 5. Curitiba: UFPR), Capra, F. (O ponto de mutação. São Paulo: Cultrix, 1993), Morin, E.; Kern, A. B. (Terra pátria. Porto Alegre: Sulina, 1995).
} 
para o exercício do saber à medida que permite a interação de vários campos diferentes sobre uma mesma problemática.

O pressuposto básico para a produção interdisciplinar do conhecimento sobre problemas ambientais adotado no âmbito do Doutorado em Meio Ambiente e Desenvolvimento da UFPR é o trabalho conjunto de diversos profissionais, oriundos de disciplinas diferentes, sobre uma problemática que tem uma mesma dimensão espacial. Considerando que os problemas ambientais se manifestam de forma concreta num espaço dado, e que a categoria espaço pode ser considerada como sendo uma manifestação de dinâmicas naturais e dinâmicas sociais, o trabalho interativo entre docentes, pesquisadores e discentes sobre uma base espacial comum permite a interação necessária para a produção objetivada do conhecimento.

Partindo deste pressuposto básico, os trabalhos da turma II foram organizados em dois grandes módulos (Figura 2), um voltado ao nivelamento e aprofundamento disciplinar (formação) e o outro à elaboração da pesquisa, desenvolvidos paralelamente e de forma a se complementarem. No primeiro, além do embasamento teórico-prático necessário à compreensão das dinâmicas naturais (ciências da natureza) e das dinâmicas sociais (ciências humanas) $)^{15}$, foi dada atenção especial à formação teórica relativa ao estudo da cidade e do urbano, para o qual se fez apelo, de forma especial, aos conhecimentos do campo da arquitetura, geografia e sociologia urbanas $^{16}$, sobretudo nos módulos III e IV.

\subsection{A elaboração da pesquisa interdisciplinar}

\subsubsection{A primeira aproximação com o objeto de pesquisa: problematizando a realidade - Oficina I}

Tendo sido definida, a priori, a problemática central de estudo, cujas questões mais gerais lançadas para investigação foram acima apresentadas, outras, que permitiram o envolvimento mais direto dos estudantes com o objeto de estudo, foram formuladas na perspectiva de possibilitar a aproximação desses estudantes à realidade e assim poder problematizá-la.

Considerando-se que boa parte dos doutorandos eram provenientes de outras cidades e que, portanto, o conhecimento sobre Curitiba e a RMC não era produto de uma vivência do contexto urbano-regional sobre o qual iriam trabalhar, decidiu-se por elaborar um diagnóstico preliminar da área de estudo. Tal qual os clássicos documentos de elaboração geográfica - inventários geográficos de espaços determinados -, este diagnóstico, elaborado principalmente a partir de dados secundários (formação histórica e elementos do sítio: componente do quadro natural) e do fato urbano (sociais, políticos e econômicos), permitiria a primeira aproximação entre sujeito e objeto da pesquisa.

Para a elaboração desse diagnóstico optou-se por abordar somente o período que vai de 1970 a 1997, este último sendo o ano de elaboração das pesquisas no âmbito do MA\&D. A década de

\footnotetext{
${ }^{15}$ As disciplinas ofertadas foram: Dinâmica dos fluxos geofísicos; Processos geológicos, geomorfológicos e pedológicos; Saúde e epidemiologia; Teoria ecológica; Elementos de antropologia, economia, sociologia; Enfoque interdisciplinar dos problemas da saúde; Práticas, usos e culturas urbanas: o projeto urbano; Industrialização, meio ambiente e os movimentos sociais; Economia, meio ambiente e desenvolvimento; Natureza, ética e educação; Educação ambiental; Comunicação e interdisciplinaridade; Metodologia de pesquisa científica e Introdução ao geoprocessamento.

${ }^{16}$ Voltadas mais diretamente ao estudo da cidade e do urbano foram ofertadas as seguintes disciplinas: O cotidiano e a metrópole e Tópicos especiais sobre a cidade e o urbano (realizada no Prourb/RJ).
} 


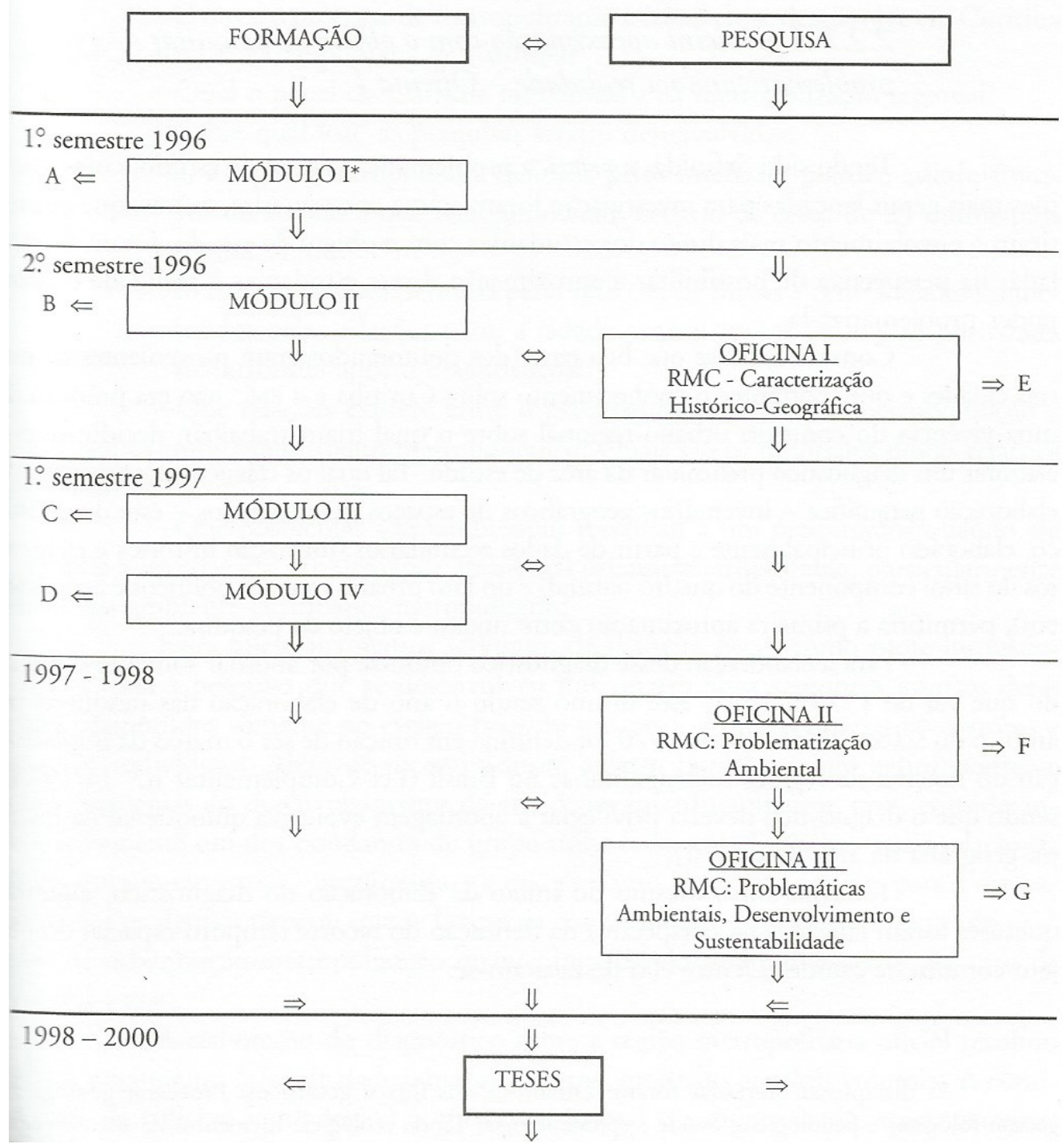

FIGURA 2 - Estudo do ambiente urbano-metropolitano de Curitiba e RMC.

* Módulo diz respeito às disciplinas ofertadas.

1970 foi definida em função de ser o marco da implantação do sistema de regiões metropolitanas no Brasil (Lei Complementar n. ${ }^{\circ}$ 14/ 1973), sendo que o diagnóstico deveria privilegiar a abordagem evolutiva quinquenal da história-geografia da área (Quadro 1).
Todavia, antes mesmo do início da elaboração do diagnóstico, algumas questões foram lançadas na perspectiva da definição do recorte têmporo-espacial do objeto comum de estudo. Dentre elas destacaram-se: 
QUADRO 1 - Caracterização evolutiva histórico-geográfica da RMC

\begin{tabular}{|c|c|c|c|c|c|c|c|}
\hline & 1970 & 1975 & 1980 & 1985 & 1990 & 1997 & \\
\hline $\begin{array}{c}\text { I. Evolução político } \\
\text { administrativa }\end{array}$ & $X$ & $\mathrm{X}$ & $\mathrm{X}$ & X & $\mathrm{X}$ & $\mathrm{X}$ & \multirow{5}{*}{$\begin{array}{l}\text { Caracterização } \\
\text { espaço-temporal } \\
\text { com ênfase } \\
\text { em cada temática }\end{array}$} \\
\hline $\begin{array}{c}\text { II. Aspectos físico- } \\
\text { naturais }\end{array}$ & $\mathrm{X}$ & $x$ & $\mathrm{X}$ & $\mathrm{X}$ & $\mathrm{X}$ & $\mathrm{X}$ & \\
\hline $\begin{array}{c}\text { III. Situação } \\
\text { socioeconômica }\end{array}$ & $\mathrm{X}$ & $\mathrm{X}$ & $X$ & $\mathrm{X}$ & $\mathrm{X}$ & $\mathrm{X}$ & \\
\hline IV. Infraestrutura & $\mathrm{X}$ & $\mathrm{X}$ & $\mathrm{X}$ & $x$ & $\mathrm{X}$ & $\mathrm{X}$ & \\
\hline \multirow[t]{2}{*}{$\begin{array}{l}\text { V. Atividades } \\
\text { econômicas }\end{array}$} & $\mathrm{X}$ & $\mathrm{X}$ & $\mathrm{X}$ & $\mathrm{X}$ & & & \\
\hline & \multicolumn{6}{|c|}{$\begin{array}{l}\text { Caracterização espaço-temporal } \\
\text { com ênfase em } \\
\text { momentos históricos distintos }\end{array}$} & $\begin{array}{c}\text { Síntese } \\
\text { histórico- } \\
\text { geográfica }\end{array}$ \\
\hline
\end{tabular}

-O que é o processo de metropolização e como ele se desenvolve em Curitiba e na RMC - Região Metropolitana de Curitiba?

- Qual o papel de Curitiba no contexto da metropolização regional?

- Sobre qual RMC as pesquisas seriam desenvolvidas:

a) a região metropolitana definida pelos interesses político-administrativos do Estado e que configurava um cenário de cerca de 25 municípios (Figura 3), ou

b) uma outra área definida pelas relações de fluxos e centralidades estabelecidos pelas relações entre a cidade central (polo) e sua área polarizada (identificada após o diagnóstico)?

- Que relações existem entre o processo de urbanização-metropolização e os problemas ambientais urbano-metropolitanos? Quais são os resultados destas relações no âmbito de Curitiba e RMC?

- Que problemas socioambientais ressaltam a um pesquisador quando ele se propõe a investigar a problemática ambiental urbano-metropolitana, particularmente quanto ao ambiente curitibano-metropolitano?

Esses questionamentos serviram, de maneira geral, como mote impulsionador a toda a pesquisa que se desenvolveu nos quatro anos seguintes, muitos deles sendo respondidos somente no estágio final do processo, nos dois programas comuns e nas teses individuais. Além de incentivadores, agiram também como aglutinadores e como estratégias do desenvolvimento de atividades interdisciplinares, pois, considerando que somente um dos estudantes do grupo tinha formação disciplinar mais relacionada aos questionamentos - arquitetura - e que, portanto, já possuía aportes para a discussão, todos os demais tiveram que se lançar ao conhecimento introdutório tanto do processo de urbanização-metropolização quanto investigá-lo preliminarmente, no caso de Curitiba e RMC.

A elaboração do diagnóstico sobre a região metropolitana oficial resultou em um documento farto de dados, mapas e textos, montado em dois volumes. A continuidade da Oficina I privilegiou a apresentação oral e a discussão dos diversos temas enfocados no diagnóstico, tendo sido possível o levantamento de inúmeros problemas socioambientais inerentes ao contexto urbano-metropolitano em estudo. No entanto, permanecia ainda o interesse individualizado dos estudantes na elaboração de suas teses, fato comum ao tradicional e já clássico processo de pós-graduação das universidades em 


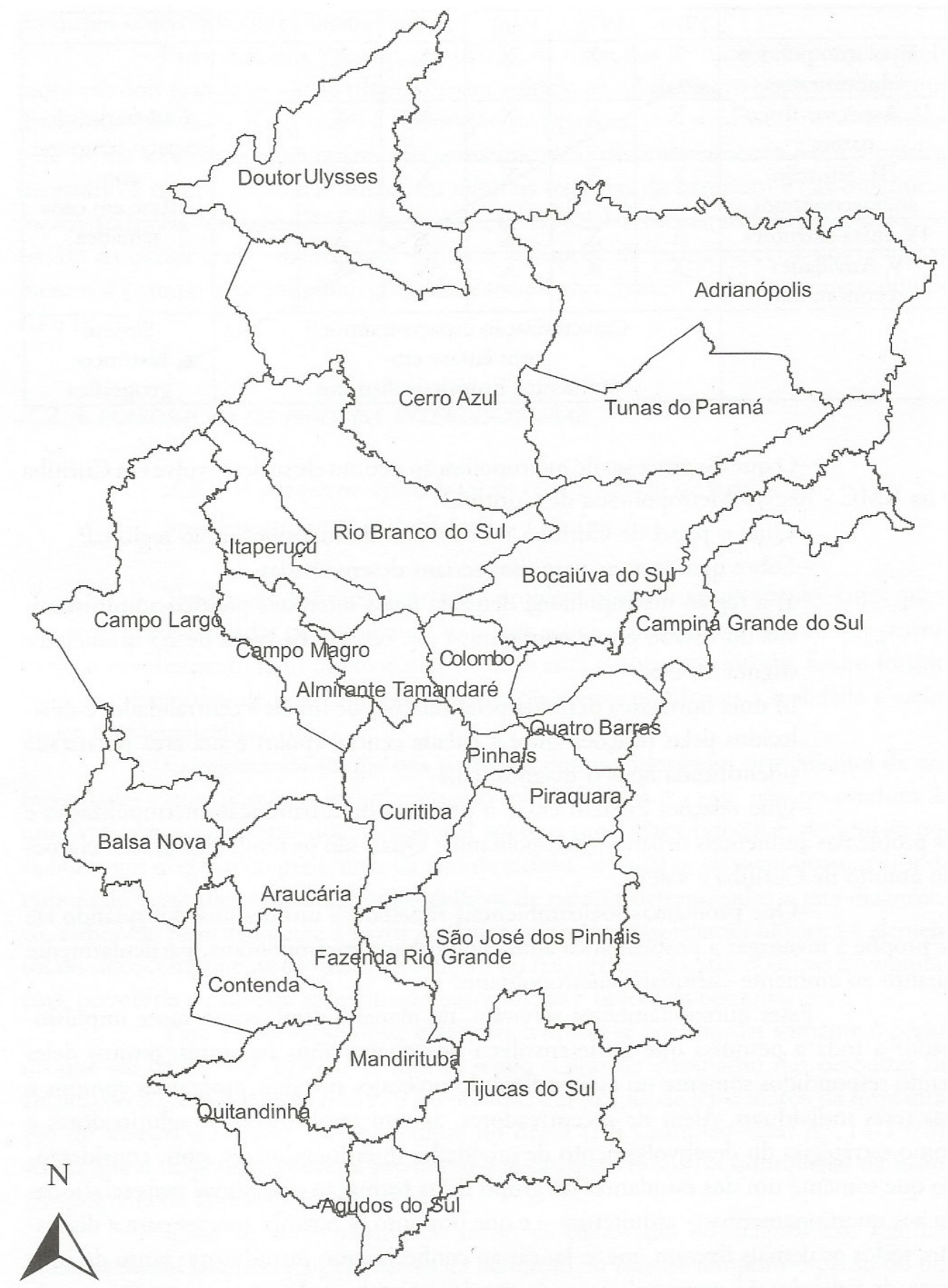

FIGURA 3 - Região Metropolitana de Curitiba - Divisão municipal.

FONTE: SEMA, 1998. Escala aproximada 1:1.000.000. 
ocidentais. Era então imperativo ultrapassar esta condição da produção disciplinar do conhecimento, era preciso tentar a interdisciplinaridade.

\subsubsection{A construção do Programa Comum de} Pesquisa: produzindo interdisciplinaridadeOficina II

As oficinas de pesquisa no âmbito do doutorado não são marcadas por nenhum tipo de ruptura, pois consistem apenas em estágios diferenciados da elaboração do trabalho de pesquisa. A sua divisão evidencia principalmente uma organização didático-pedagógica da pesquisa e permite identificar as diversas dimensões do trabalho coletivo (Programa Comum), bem como aquela do individual (Projeto de Tese) e o necessário aprofundamento teórico-prático do processo.

Considerando o trabalho elaborado até aquele momento, o diagnóstico preliminar e os debates que se seguiram ao e sobre o mesmo, permanecia a questão central:

- Como proceder à investigação interdisciplinar da realidade urbano-metropolitana de Curitiba e de algumas de suas problemáticas?

Parecia necessário partir-se então dos interesses individuais dos estudantes em relação a algumas problemáticas e averiguar as possíveis interações entre os interesses, fato que levaria tanto à possibilidade da construção de problemáticas comuns quanto ao desenvolvimento de temáticas e problemáticas de interesse particular.

Neste contexto, procedeu-se primeiramente a uma tentativa de identificação de agentes e atores que se destacam no processo de produção do espaço e da realidade urbano-metropolitana em estudo, bem como das principais atividades, demandas e problemas evidenciados pelo diagnóstico elaborado na área de estudo. Assim, e exercitando uma prática desenvolvida pela turma $\mathrm{I}^{17}$ (definição de uma grade de pesquisa), buscou-se construir problemáticas comuns de pesquisa que fossem derivadas das interações e dinâmicas estabelecidas por agentes e atores nas suas práticas cotidianas sobre a realidade estudada (Figura 4). Esta atividade não logrou o êxito esperado, no entanto, serviu para realçar problemas socioambientais característicos da RMC, bem como colocar em evidência a interação de alguns deles com as instâncias de poder sobre a cidade e a região metropolitana, o que permitia ao grupo se aproximar cada vez mais do objeto de estudo.

Uma outra estratégia resultante dos debates estabelecidos no âmbito das reuniões das oficinas por grupos de estudantes em particular e/ou com o corpo docente foi então tentada na perspectiva da construção de um programa interdisciplinar de pesquisa sobre a RMC. Neste estágio de desenvolvimento do trabalho, foram definidos alguns eixos aglutinadores de interesses que, utilizados como norteadores para uma revisão analítica e crítica do diagnóstico elaborado e dos debates travados, poderiam resultar na construção de problemáticas comuns de pesquisa.

Este exercício permitiu a definição de uma abordagem comum a todos os estudantes, seja nos programas comuns de pesquisa, seja nas próprias teses individuais, e que viria a se constituir numa parte do trabalho interdisciplinar que permitiria a eles uma primeira interação. Trata-se do levantamento bibliográfico, dos debates e da elaboração de uma sólida e bem argumentada fundamentação teórica relativa aos conceitos de ambiente, de-

\footnotetext{
17 Para o desenvolvimento desta atividade buscaram elementos auxiliares no trabalho elaborado pela turma I do Programa de Doutorado em Meio Ambiente e Desenvolvimento sobre o litoral paranaense.
} 


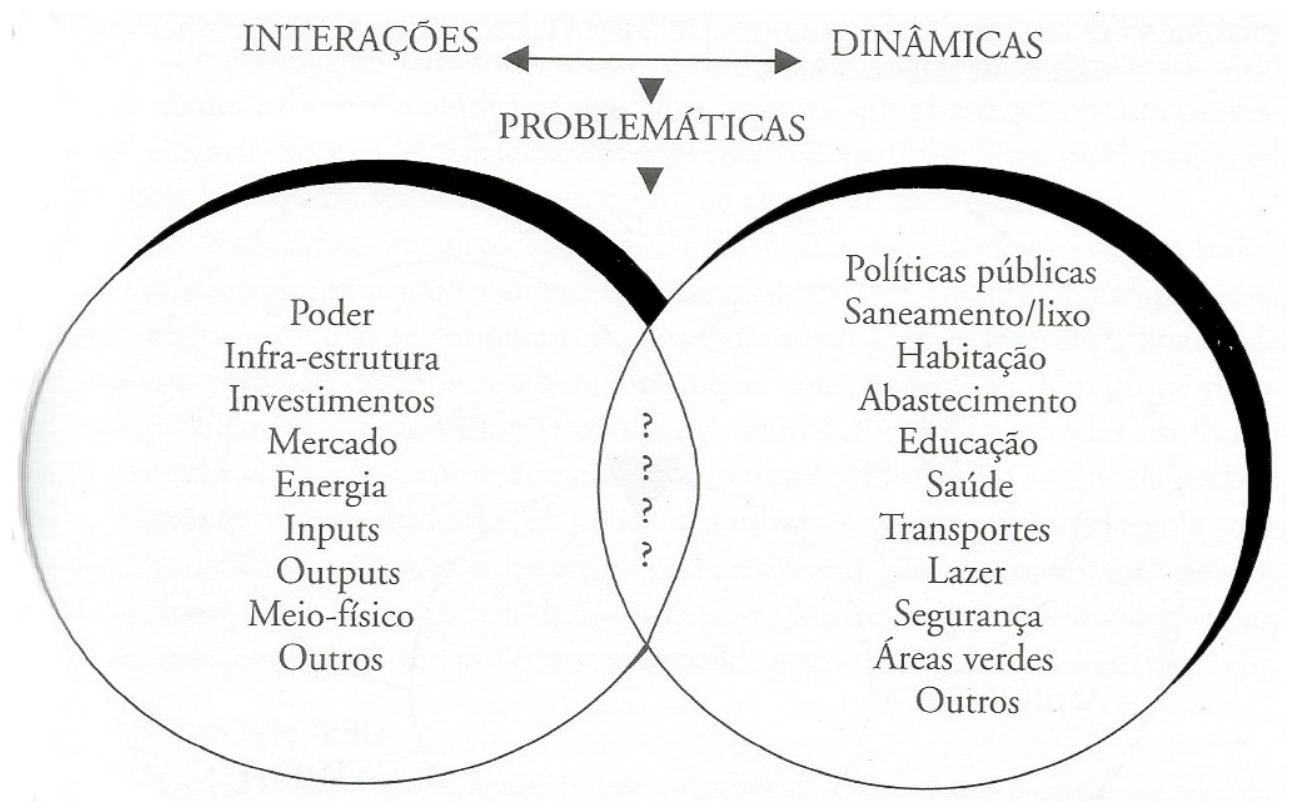

FIGURA 4 - Interações e dinâmicas de agentes e atores na construção de problemáticas de pesquisa na RMC.

senvolvimento e metropolização; afinal, algumas questões comuns se colocavam como primordiais a todos os integrantes do grupo, tais como: banos?

- O que são problemas socioambientais ur-

- Qual a particularidade dos problemas ambientais em contexto urbano-metropolitano?

- Impõe o processo de metropolização lógicas diferenciadas de desenvolvimento?

- Que implicações podem ser observadas na ideia de desenvolvimento sustentável em contexto urbano-metropolitano?

- Como se dá a repercussão do processo de metropolização sobre os recursos naturais e sobre o ambiente?

Definida esta primeira instância de interações - a construção de um quadro comum de referências teóricas do tripé ambiente-desenvolvimento-urbanização, foi então possível, sobretudo devido aos debates acerca dos questionamentos apresentados e aos elementos do diagnóstico preliminar, elaborar uma primeira aglutinação de temáticas (Figura 5) alicerçada em três dimensões, assim constituídas: 1. ALÓGICA DAS POLÍTICAS PÚBLICAS: Nesta, identificou -se a perspectiva da abordagem de políticas públicas, da questão florestal, do planejamento urbano e das ações do poder público na gestão do ambiente, a partir do uso de redes de informações.

2. A LÓGICA DA PRODUÇÃO: Nesta perspectiva foram identificados interesses relativos a problemas do meio rural, particularmente das práticas agrícolas em contexto metropolitano, das condições de pobreza e mercado de trabalho, bem como dos processos de apropriação e reprodução do espaço e das atividades industriais em sua interação com o ambiente.

3. A LÓGICA DOS RECURSOS: Nesta lógica elencaram tanto recursos naturais (particularmente os recursos hídricos - água) quanto aqueles neces- 


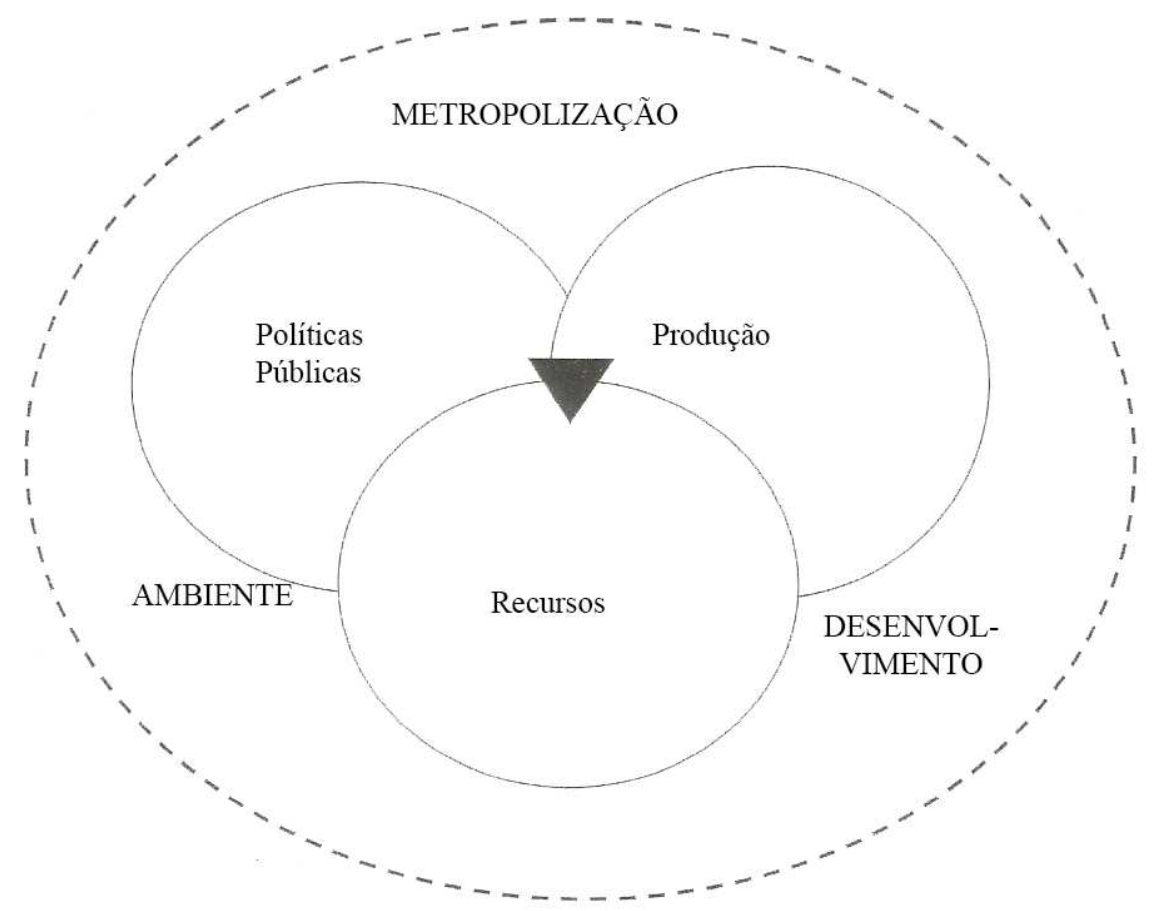

FIGURA 5 - Eixos aglutinadores de temáticas para a pesquisa interdisciplinar sobre a RMC.

sários ao estabelecimento dos espaços urbano-metropolitanos e da vida urbana, como os recursos de educação e de saúde.

\subsubsection{Do Programa Comum de Pesquisa à} Tese Individual e vice-versa: desenvolvendo a interdisciplinaridade - Oficina III

Estabelecida a perspectiva de leitura de problemas socioambientais ocorrentes na RMC a partir da lógica das políticas públicas, da produção e dos recursos, passou-se então à tentativa da construção de uma problemática comum de pesquisa, portanto ampla o suficiente para aglutinar os diferentes interesses em jogo entre os estudantes. Mais uma vez não se obteve sucesso no objetivo geral da metodologia de trabalho interdisciplinar em curso, pois não foi possíve $l^{18}$ construir um programa comum de pesquisa aglutinador dos 14 interesses envolvidos no estudo das condições e qualidade de vida em Curitiba e RMC, mas dois subprogramas.

De todo modo, restou ao grupo uma perspectiva de interação teórica, aquela da instância de discussões dos fundamentos básicos comuns às pesquisas: a da interação entre o ambiente, o desenvolvimento e a metropolização; além destes,

${ }^{18}$ Há que se salientar que a impossibilidade de construção de um único programa de pesquisa deveu-se sobretudo a problemas de ordem pessoal manifestados em consideráveis diferenças entre os estudantes, fato que revelou a necessidade primeira da existência de grande empatia e predisposição para o trabalho conjunto e coletivo entre os membros de uma proposta interdisciplinar. A atuação de um psicólogo na dinâmica de grupo pareceu necessária ao desempenho satisfatório de uma experiência interdisciplinar. 
também o resgate do processo histórico da constituição e evolução da RMC nos últimos 30 anos era uma perspectiva de abordagem comum a todos os doutorandos. Foi nesta dimensão, a do aprofundamento e discussão teórica de temáticas comuns, que se estabeleceu um processo interdisciplinar entre os 14 participantes da turma II e, partindo desse nível mais geral de interações, o trabalho foi se hierarquizando até chegar às teses individuais.

Guardadas essas preocupações e a perspectiva de elaboração de um trabalho comum, mesmo praticando a interdisciplinaridade exclusivamente no campo teórico, dois subgrupos então se formaram e construíram programas interdisciplinares de pesquisa com enfoques distintos, embora fortemente complementares. Um grupo construiu sua problemática tendo como preocupação central a manifestação das condições de vida na cidade, elegendo como cerne de sua atenção as dimensões sociais da problemática ambiental urbana derivadas de políticas públicas, e o outro grupo elegeu a problemática derivada da interação entre o processo de urbanização-metropolização na RMC e seus impactos sobre os recursos hídricos urbano-regionais; a água sendo colocada no centro das atenções a partir das políticas e práticas de gestão ambiental da área (Figura 6).

Para o primeiro grupo, a discussão dos problemas ambientais urbano-metropolitanos de Curitiba e RMC situou-se, principalmente, no campo do desenvolvimento humano e seus indicadores apontados pela ONU por meio do IDH (Índice de Desenvolvimento Humano). Ainda que tenha havido uma importante interação entre os membros da equipe nas discussões de primeira ordem (metropolização, meio ambiente e desenvolvimento), a parte mais importante do processo parece ter se dado quando da abordagem do desenvolvimento humano e seus desafios; desta dimensão (segunda ordem) para a elaboração das teses individuais (terceira ordem de interações), a produção interdisciplinar deu-se de maneira bastante tênue, pois somente dois estudantes trabalharam a mesma temática (agricultura orgânica - indicadores e o "novo rural"), com enfoques diferenciados.

Para o segundo grupo, que elegeu trabalhar com políticas e práticas de gestão em Curitiba e RMC, as interações entre os estudantes na produção interdisciplinar do conhecimento revelaram-se de maneira mais explícita que no outro grupo. Tendo colocado no centro de suas preocupações as relações entre as práticas sociais e os recursos hídricos, notadamente a degradação destes face às ações daquelas, foi então possível elaborar um programa comum de pesquisa que possibilitou um melhor exercício de interdisciplinaridade entre os diferentes objetivos. Para tanto, elegeu-se a porção leste da RMC (espaço comum aos projetos de tese), área com graves problemas relativos à degradação dos recursos hídricos (mananciais de abastecimento público de água) face à pressão do processo urbano-industrial que sobre ela se desenvolve no presente, fato que explicita condições limitantes ao desenvolvimento da região. Este grupo trabalhou então com uma mesma base de pressupostos teóricos, espaço geográfico e problemática comum de pesquisa, o que facilitou sobremaneira o exercício da interdisciplinaridade almejada.

Destes dois grupos, que a partir de um determinado momento do trabalho interdisciplinar elaboraram seus estudos em pequenos grupos e depois individualmente, resultaram 13 teses que foram defendidas publicamente perante bancas examinadoras entre agosto de 2000 e fevereiro de 2001, e cujos títulos estão apresentados a seguir.

A breve descrição do processo de produção interdisciplinar do conhecimento acerca do ambiente urbano-metropolitano aqui exposta permite observar diversas formas de interação na elaboração desta nova modalidade acadêmica. Dito de outra forma, pode-se constatar diferentes instâncias do trabalho interdisciplinar, sendo que há instâncias e aborda- 


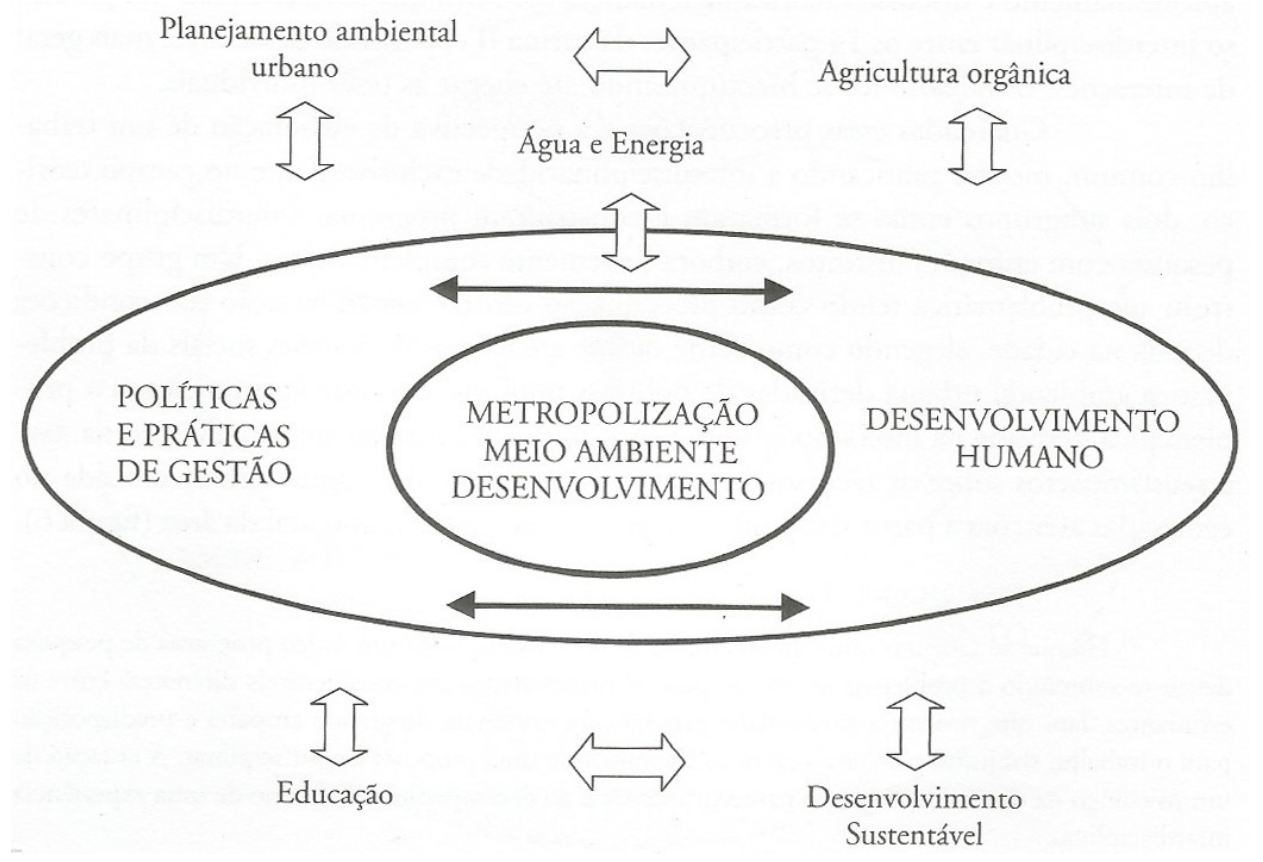

FIGURA 6 - RMC - Região Metropolitana de Curitiba-PR: esquema do programa comum de pesquisa.

gens que podem ser elaboradas em grandes grupos e que vão se refinando à medida que as problemáticas exigem maior detalhamento, exigindo assim a interação entre um número menor de pessoas. Parte-se de programas comuns a um número maior de interessados, com questões e preocupações de ordem mais geral, até se chegar às teses individuais, passando por interesses e objetivos que estão na esfera de subgrupos e de indivíduos.

Esta produção diferenciada do conhecimento resulta em muitas inovações. A leitura da cidade e do urbano, de maneira explícita e flagrante, é bastante diferenciada das leituras tradicionais dos campos disciplinares individualmente, fruto direto da riqueza do conhecimento e experiência de profissionais originários de campos do conhecimento que, a priori, não tomam a cidade como cerne de suas preocupações. Neste sentido, e buscando a análise do ambiente urbano-metropolitano, os resultados culminam com uma abordagem da cidade que em muito supera os tradicionais enfoques da ciência moderna. Constrói-se, assim, uma nova perspectiva para o equacionamento dos problemas ambientais urbano-metropolitanos contemporâneos.

O leitor poderá buscar respostas para os inúmeros questionamentos lançados durante o processo da construção interdisciplinar da turma II e apresentados no corpo do presente texto. Muitas delas compõem os resultados das teses defendidas (listadas a seguir), o que desperta a curiosidade para o conhecimento detalhado. Muitos daqueles questionamentos continuam ainda sem resposta, pois a iniciante pesquisa do ambiente urbano de forma interdisciplinar somente agora começa a se estruturar no meio científico-técnico. O esboço aqui apresentado constitui-se numa pequena e ousada partícula de um projeto maior para uma nova compreensão e gestão da cidade. 


\section{Teses defendidas}

\subsection{Programa Desenvolvimento Humano na RMC}

Título Agricultura orgânica: estratégia para uma nova ruralidade.

Autor Karen Follador Karam.

Título Curitiba 1900-1973: da espacialidade extrativista à cidade-jardim.

Autor Miguel Arturo Curoto de Oliveira.

Título As dimensões da sustentabilidade: um estudo da agricultura orgânica na Região Metropolitana de Curitiba - PR.

Autor Moacir Roberto Darolt.

Título Precarização do trabalho e condições de vida: a situação da Região Metropolitana de Curitiba nos anos 90.

Autor Paulo Roberto Delgado.

Título Em busca de uma cidade para a vida: a sustentabilidade urbana e a produtividade social em Natal $\mathrm{RN}$ e região ${ }^{19}$.

Autor Rinaldo Claudino de Barros.

Título Gravidez na adolescência: um estudo de desenvolvimento humano e meio ambiente em uma vila de recicladores de lixo em Curitiba.

Autor Sonia Maria Davanso.

\subsection{Programa Políticas e Práticas de Gestão Ambiental na RMC}

Título Sistemas de informações e gerenciamento de recursos hídricos na Região Metropolitana de Curiti$b a-P R$ : entre a norma prescrita e a conduta concreta.

Autor Alberto Pucci Junior.

Título A ocupação de áreas de mananciais e os limites dos recursos hídricos na RMC: do planejamento à gestão ambiental urbana-metropolitana.

Autor Cristina de Oliveira Lima.

Título O meio físico e a ocupação urbana de Curitiba - PR: estudo de caso.

Autor Emilio Trevisan.

Título Formação de formadores em educação ambiental nos cenários da RMC: das resistências aos fatos.

Autor Gastão Franco da Luz.

Título Idosos: condições de vida, saúde e nutrição no município de Curitiba - PR.

Autor Patrícia Teixeira Silva Penteado.

Título Redes e poder: o processo de metropolização e a gestão dos recursos naturais.

Autor Rodolfo Humberto Ramina.

Título Avaliação da qualidade da água na bacia do Alto Iguaçu através da modelagem matemática para planejamento e gestão de recursos hídricos.

Autor Tânia Lúcia Graff de Miranda.

19 Esta foi a única tese elaborada que teve como objeto de estudo final uma cidade localizada fora do âmbito da Região Metropolitana de Curitiba. O autor interagiu com todo o grupo durante mais de dois anos de elaboração do trabalho interdisciplinar e, no final do processo, teve que retornar à sua cidade de origem; aproveitando as bases da discussão sobre a relação cidade-ambiente urbano-desenvolvimento, pôde elaborar um estudo sobre a cidade de Natal - RN. 


\section{Referências}

Araujo, T. B. A experiência do planejamento regional no Brasil. In: Lavinas, L. et al. (Org.). Reestruturação do espaço urbano e regional no Brasil. São Paulo: Anpur; Hucitec, 1991, p. 87-96.

Desenvolvimento e Meio Ambiente. Curitiba: UFPR, 1994-2002.

Capra, F. O ponto de mutação. São Paulo: Cultrix, 1993.

Harvey, D. A condição pós-moderna. São Paulo: Hucitec, 1992.

Hobsbawn, E. Era dos extremos: o breve século XX (19141991). São Paulo: Companhia das Letras, 1998.

Lefebvre, H. O direito à cidade. São Paulo: Moraes, 1991.

Lopes, R. A cidade intencional: o planejamento estratégico de cidades. Rio de Janeiro: Mauad, 1998.

Mendonça, F. A. Geografia, planejamento urbano e ambiente. In: Souza, A. J. et al. (Org.). Paisagem, território, região: em busca da identidade. Cascavel, PR: UniOeste/ AGB, 2000. p. 39-48.

Monteiro, C. A. F. Teoria e clima urbano. São Paulo: Igeo/ USP, 1976.

Morin, E.; Kern, A. B. Terra pátria. Porto Alegre: Sulina, 1995.

Munford, L. A cidade na história. Belo Horizonte: Itatiaia, 1965.

Santos, M. O espaço dividido. Rio de Janeiro: Francisco Alves, 1979.

Santos, M. A urbanização brasileira. São Paulo: Hucitec, 1993.

Santos, M. A natureza do espaço: técnica e tempo, razão e emoção. São Paulo: Hucitec, 1996.

Tarlet, J. La planification ecologique. Paris: Economica, 1985. 